\title{
Sensitivity analysis applied to the evaluation of earthquake damage in historic towers
}

\author{
S. Ientile \& S. Russo \\ Department of Design and Planning in Complex Environments, \\ IUAV University of Venice, Italy
}

\begin{abstract}
Masonry towers are part of the wide Italian architectural heritage, and in many cases are a distinctive character of town centres. This structural type has a greater vulnerability than most masonry buildings due to its vertical development subjecting the structure to significant risks, as a function of the high tensile stress at the base, the effects of thermal variations and the dynamic effects of seismic events. Observing the damage of existing structures during past earthquakes, Italian legislation for cultural heritage (LL.GG. 2011) has identified the most common failure modes of different building typologies, in order to evaluate the dynamic behaviour of structures. The global collapse mechanisms of towers are nearly related to the geometry of the structure, the construction technology and material, the soil and the foundation structure. This paper investigates the methods of analysis and assessment of the damage of a case study such as the Tower of St. Stefano di Sessanio (AQ), struck by the L'Aquila earthquake of April 6, 2009, which caused its total collapse. A simplified mechanical model and a FE model were used to estimate the possible causes of the collapse, and a sensitivity analysis was carried out to evaluate the results.

Keywords: heritage masonry buildings, seismic vulnerability, FE model, historical towers, damage assessment.
\end{abstract}

\section{Introduction}

Masonry towers have had a variety of uses both as places of worship and as strategic and military buildings. For this reason their structural heterogeneous configurations are mainly distinguished in four categories: civic towers, belltowers, tower-houses and towers enclosed in the city walls. The common 
distinctive character is the vertical development, subjecting the structure to significant risks as a function of the high tensile stress at the base, the effects of temperature variations and seismic actions or actions arising from the motion of the bells. Furthermore, crushing phenomena in the masonry are encouraged by the high vertical loads.

The dynamic behaviour of masonry structures is deeply influenced by the geometric relationships and the state of material conservation (Anzani et al. [1]). From the observations of the damage caused by past earthquakes (Friuli 1976, Reggio-Emilia 1996, Umbria-Marche 1998, L'Aquila 2009) it is possible to distinguish the most frequent failure modes in order to evaluate the behaviour of buildings and to consider them for the analysis and calculation methods (Boscato et al. [2]). From this information, Italian normative reference for existing masonry buildings LL.GG. 2011 [3] proposes simplified mechanical models allowing one to obtain useful information comparable with more refined numerical models in order to evaluate the damage and the potential causes of collapse.

This paper presents the study of the Tower of S. Stefano di Sessanio, stricken by L'Aquila earthquake of April 6 2009, which caused its total collapse. Through the simplified method, it is performed a first evaluation of the damage and its causes. A finite element model is used to perform dynamic modal in order to identify the causes of the collapse comparing to the results of mechanical model. A sensitivity analysis is performed on both models' results to estimate the influence of structure's features.

\section{Failure and damage of historic towers}

The observations and surveys conducted on existing towers hit by earthquakes have resulted in the identification of typical failure mechanisms. They are divided into global mechanisms and mechanisms in the belfry (Di Tommaso and Casacci [4]).

The global mechanisms typical of the towers occur in dependence on the efficacy of the connection of the masonry walls (Russo [5]), ensuring an overturning mechanism of the structure with a diagonal cracked surface. When the connection between the walls is insufficient, or the structure is already damaged, the collapse mechanism is constituted by a general phenomenon of disintegration of the masonry walls. It is characterized by the opening of vertical cracks compromising the overall behaviour of the tower. The second type refers to mechanism related to the presence of the belfry on the top of the tower that supports and protects the bell system usually characterized by large openings (Ivorra et al. [6]).

\subsection{Mechanisms of seismic damage}

In general, the typical mechanisms of the seismic collapse are influenced by the geometric characteristics of the tower but also by the manufacturing technology, the material quality, the performance of the underlying soil and the foundation 
structure (Casalegno et al. [7]). This latter aspect is not secondary, since the type of structures such as towers are dynamically very sensitive to the deformability of the ground below. To simplify the analysis, three main configurations are considered: isolated tower, adjacent tower or tower overlying to church. Related to the ideal situation of "isolated tower", six major damage situations referring specifically to the kinematics can be identified (Doglioni et al. [8]) (fig. 1).
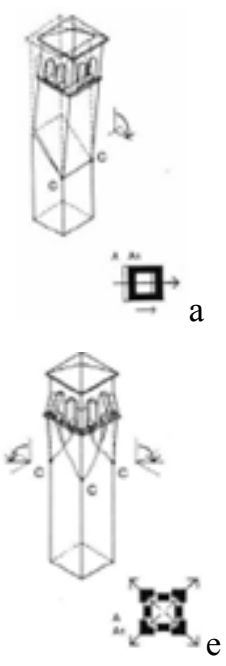
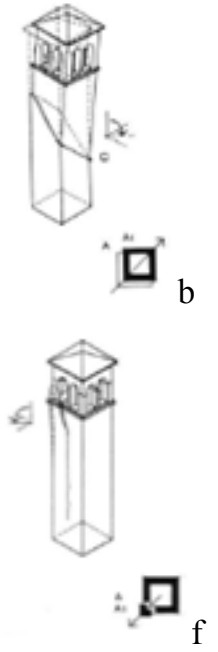
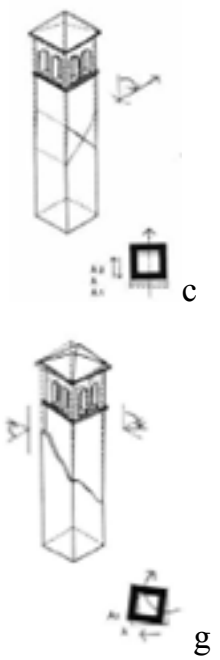
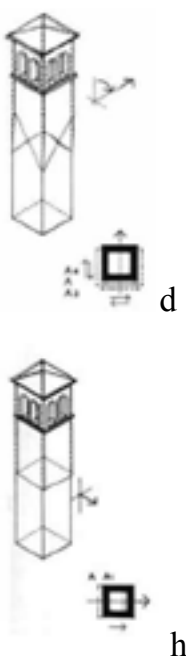

Figure 1: The main seismic damage mechanism for masonry towers (Doglioni et al. [8]).

- outward rotation of the upper part of the bell tower due to out-of-plane actions, with formation of a cylindrical hinge with a horizontal axis or spherical hinge in correspondence of a point or an edge (fig. 1a-b);

- translation of the upper wall of the bell tower, followed by rotation of the same (fig. 1c-d);

- outward rotation of "spheres of angled" around a hinge point, the lower end of the affected part from the mechanism (fig. 1e);

- outward rotation of one or more angled with horizontal axis of rotation parallel to the side or the diagonal (fig. 1f), rotation of the upper part of the tower, resulting from the combination of a rotation around a vertical axis and a rotation around a horizontal axis (fig. 1g);

- translation of the upper part (fig. 1h).

\section{A simplified mechanical model}

In order to understand the behaviour of masonry towers, the structural model finds its foundations in the laws of kinematics simplifying the geometry of the 
problem. The slenderness is a parameter that strongly influences the dynamic behaviour of a tower: a squat structure exhibits shear failure, instead of a slender structure behaves as one-dimensional element with a cantilever behaviour. The connection between the walls is important to ensure that it behaves as a shelf constrained at the base with stiffness related to the whole wall section.

On these hypotheses, LL.GG.2011 study the seismic behaviour of the towers using a simplified mechanical model by referring to the collapse by flexuralaxial loads, whereas the tower as a shelf under a system of horizontal forces (fig. 2). The crisis is determined by crushing in the compression zone in a generic section due to no tensile strength.

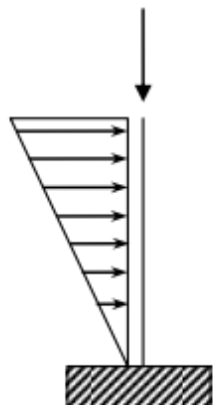

Figure 2: $\quad$ Static simplified scheme.

By dividing the structure into n-sectors of uniform geometric characteristics, the subsequent test sections are identified for the flexural-axial loads verification, comparing the moment resisting with no tensile strength assumption. The moment resisting of $\mathrm{i}$-th sections is:

$$
M_{u, i}=\frac{\sigma_{0 i} A_{i}}{2}\left(b_{i}-\frac{\sigma_{0 i} A_{i}}{0,85 a_{i} f_{d}}\right)
$$

With $\sigma_{0 \mathrm{i}}$ average normal stress in the analysis section, $\mathrm{A}_{\mathrm{i}}$ the total area of the analysis section purified from openings, $b_{i}$ and $a_{i}$ respectively parallel and perpendicular side to the direction of the seismic force of the considered i-th analysis section, adjusted by the length of the openings, $f_{d}$ compressive strength of the masonry; and the related moment generated by the horizontal force:

$$
\mathrm{F}_{\mathrm{h}}=0,85 \mathrm{~S}_{\mathrm{e}}\left(\mathrm{T}_{1}\right) \mathrm{W} / \mathrm{q}
$$

With $\mathrm{S}_{\mathrm{e}}\left(\mathrm{T}_{1}\right)$ ordinate of the elastic response spectrum, according to the first period $\mathrm{T} 1$ of the structure according to the direction considered, $\mathrm{W}$ the total weight of the structure and $\mathrm{q}$ behaviour factor.

For the evaluation of vulnerability of the tower, equalling the expressions of resistance moment and the moment of horizontal actions, it is assessed the value of the ordinate of the elastic response spectrum of reaching the limit state for the i-th section:

$$
\mathrm{S}_{\mathrm{e}, \mathrm{SLV}, \mathrm{i}}\left(\mathrm{T}_{1}\right)=\frac{\mathrm{q} \mathrm{M}_{\mathrm{u}, \mathrm{i}} \sum_{\mathrm{k}=1}^{\mathrm{n}} \mathrm{z}_{\mathrm{k}} \mathrm{W}_{\mathrm{k}}}{0,85 \mathrm{~W}\left(\sum_{\mathrm{k}=\mathrm{i}}^{\mathrm{n}} \mathrm{z}_{\mathrm{k}}^{2} \mathrm{~W}_{\mathrm{k}}-\mathrm{z}_{\mathrm{i}} * \sum_{\mathrm{k}=\mathrm{i}}^{\mathrm{n}} \mathrm{z}_{\mathrm{k}} \mathrm{W}_{\mathrm{k}}\right) \mathrm{Fc}}
$$


With $z_{k}$ height of the centre of gravity of the mass of the k-th sector relative to the base, having a weight $\mathrm{W}_{\mathrm{k}}, \mathrm{z}_{\mathrm{i}}{ }^{*}$ height of the $\mathrm{i}$-th verification section related to the base.

The failure is reached in the section with the minimum spectral acceleration, also defined as a function of the confidence factor Fc.

This value, according to LL.GG. 2011, is always between 1 and 1.35 and it represents the uncertainties of geometrical and mechanical parameters relating to the knowledge of the structure.

\section{Sensitivity analysis}

The mathematical models for the analysis of structures are an approximation of reality, the results are then affected by uncertainties. For the assessment of the structure, it is important to identify the sensitivity and the importance of the model parameters. Thus it is evaluated the influence on the output value with respect to the variation of input parameters, such as the mechanical characteristics of materials, the geometry and then by the role of the structural elements. To assess the sensitivity of a structural model and the choice of its parameters, it is calculated the variation of the response as a function of the change in input parameters or model configurations (Mendes and Lourenço [9]).

\subsection{Finite input variation}

Among the various techniques of sensitivity analysis, the Finite Input Variation (FIV) technique belongs to the category one-at-a-time sensitivity techniques (Fassò and Perri [10]). The method involves to vary the chosen variable input $\lambda$ of a finite amount $D \%$ and calculates the related change in output y, provided by the model:

$$
\mathrm{V}_{\mathrm{j}}(\mathrm{t})=\frac{\mathrm{y}\left(\lambda_{1,0} \ldots \lambda_{\mathrm{j}, 0}+\mathrm{D} \%, \ldots \lambda_{\mathrm{n}, 0}, \mathrm{t}\right)}{\mathrm{y}\left(\lambda_{1,0} \ldots \lambda_{\mathrm{j}, 0}-\mathrm{D} \%, \ldots \lambda_{\mathrm{n}, 0}, \mathrm{t}\right)}
$$

when the value $V_{j}=1$, the sensitivity of the output to the input is negligible.

\section{The Tower of S. Stefano di Sessanio}

The object of this paper is the Tower of S. Stefano di Sessanio (AQ), a Medici tower of XIV century and a symbol of the same village. It was hit by the L'Aquila earthquake of April 6 2009, which caused its total collapse. The building was the crowning place of the village because of its function of warning and defence, free of external constraints side. The tower had a cylindrical structure with a diameter base of $7 \mathrm{~m}$ and a height of $18 \mathrm{~m}$, the circular cross section is constant along the development of the tower with a thickness equal to $1.50 \mathrm{~m}$. Inside there were two horizontal wooden floors connected by a wooden staircase, with a total thickness of $10 \mathrm{~cm}$. Below the battlements of the top, there was a slab-circular plate in concrete with a thickness of about $15 \mathrm{~cm}$, executed around 1960-1970. The connection between the plate and the crown wall was a 
depth of $20 \mathrm{~cm}$, while the wooden floors were poorly anchored to the apparatus walls. After the collapse, it was observed that the concrete slab has been preserved falling to the side of the tower, unlike the other remains consisting of scattered rubble.

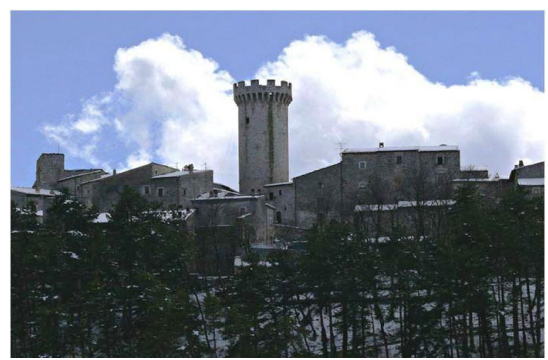

(a)

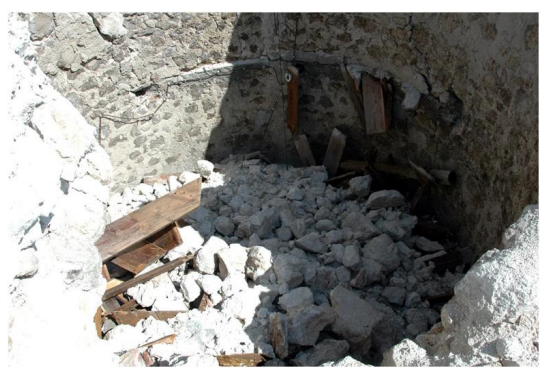

(c)

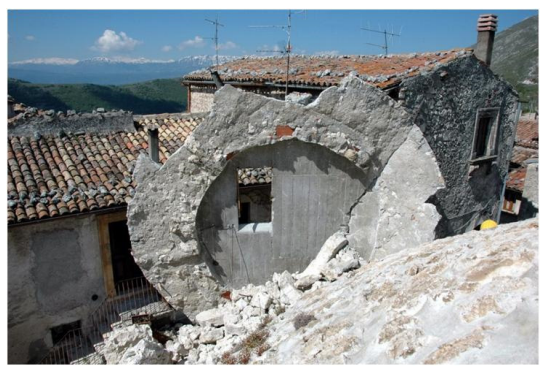

(b)

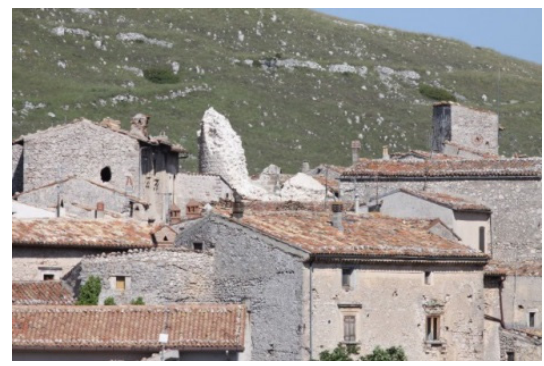

(d)

Figure 3: The Tower of S. Stefano di Sessanio before (a) and after (b)-(d) the earthquake.

\subsection{Sensitivity FE model}

It was built a finite element numerical model using shell elements, attributing the mechanical parameters of density $\mu$, Young Modulus E and Shear Modulus $G$ to the different structural parts. The wood floors were been neglected in modelling unlike the reinforced concrete slab, located at the top, of which one wanted to assess the influence on the dynamic response of the tower. The mechanical parameters used in the FE model are: $\mu=1800 \mathrm{~kg} / \mathrm{m}^{3}, E x=45000 \mathrm{~kg} / \mathrm{cm}^{2}$ and $E y=27000 \mathrm{~kg} / \mathrm{cm}^{2}$ and $\mathrm{G}=15000 \mathrm{~kg} / \mathrm{cm}^{2}$ for masonry; $\mu=2700 \mathrm{~kg} / \mathrm{m}^{3}$, $\mathrm{E}=120000 \mathrm{~kg} / \mathrm{cm}^{2}$ and $\mathrm{G}=48000 \mathrm{~kg} / \mathrm{cm}^{2}$ for stone battlements; $\mu=2500 \mathrm{~kg} / \mathrm{m}^{3}$, $\mathrm{E}=250000 \mathrm{~kg} / \mathrm{cm}^{2}$ and $\mathrm{G}=100000 \mathrm{~kg} / \mathrm{cm}^{2}$ for concrete slab. Then it is used a linear elastic model to carry out a dynamic analysis in order to determine modal frequencies and mode shapes of the structure. The modal analysis was performed in the two configurations (fig. 4), in order to evaluate the sensitivity of the dynamic response to the presence of this structural element. Comparing the modal frequencies of the two configurations, it is noticed that the first ten modes have almost equal values. The values of the subsequent modes are visibly 
higher in the concrete slab model. This is because the higher modes are influenced by the presence of this element of lower elasticity than the masonry, in fact the mode shapes are constituted by local modes of the slab and battlements at the top. The influence of concrete slab is negligible on the dynamic response of the tower, which is insensitive to its presence.

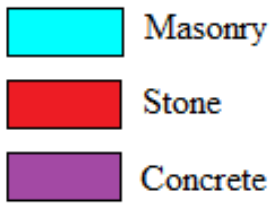

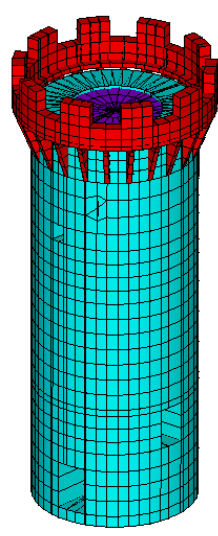

(a)

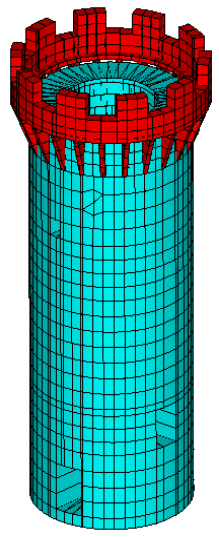

(b)

Figure 4: The two model configurations: with (a) and without (b) concrete slab.

In order to evaluate the collapse causes, the first ten modes of vibration of the structure can be considered representative of the dynamic behaviour referring to both configurations.

Table 1: Modal frequencies of the two model configurations.

\begin{tabular}{|c|c|c|c|}
\hline \multirow{2}{*}{ MODE } & MODEL CONCRETE SLAB & MODEL NO SLAB & \multirow{2}{*}{$\begin{array}{c}\text { Percentage } \\
\text { variation } \\
(\%)\end{array}$} \\
\hline & frequency $(\mathrm{Hz})$ & frequency $(\mathrm{Hz})$ & \\
\hline 1 & 3.24 & 3.30 & $2 \%$ \\
\hline 2 & 3.34 & 3.40 & $2 \%$ \\
\hline 3 & 7.02 & 7.06 & $1 \%$ \\
\hline 4 & 12.35 & 12.42 & $1 \%$ \\
\hline 5 & 12.45 & 12.53 & $1 \%$ \\
\hline 6 & 17.01 & 17.63 & $4 \%$ \\
\hline 7 & 19.43 & 18.31 & $-6 \%$ \\
\hline 8 & 20.86 & 18.36 & $-12 \%$ \\
\hline 9 & 22.52 & 20.94 & $-7 \%$ \\
\hline 10 & 22.64 & 23.78 & $5 \%$ \\
\hline
\end{tabular}

As regards the mode shapes, the characteristic of symmetry is evidenced by equal flexural modes in all directions. The behaviour is typical of a fixed beam, 
with maximum displacement in correspondence with the top and the high part of the stem. The main mode shapes of the tower, resulting from dynamic analysis, could be associated to typical overturning mechanism according to modal displacement and also to ruins of the tower (fig. 5).

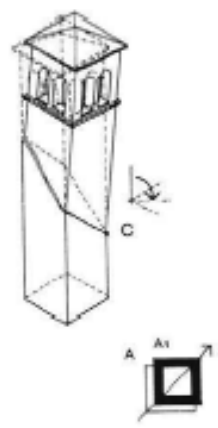

(a)

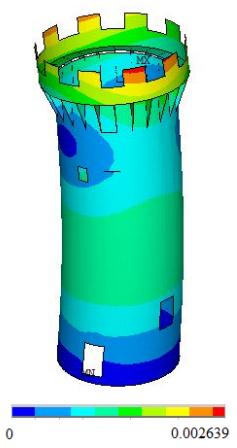

(b)

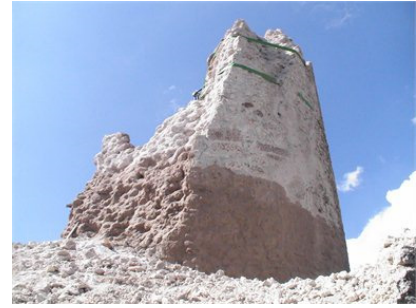

(c)

Figure 5: Typical failure mechanism of tower (a) compared to ruins of case study (c) and mode shape FE model (b).

Therefore the concrete slab is to be excluded as a cause of the collapse of the tower, as it was possible to verify that it does not influence the dynamic characteristics of the structure (as shown by percentage variation in table 1). The observed mode shapes affect the stem, fig. 5(b), and only in the highest modes are local mechanisms activated concerning attached structural parts i.e. the stone battlements and concrete slab (fig. 6).

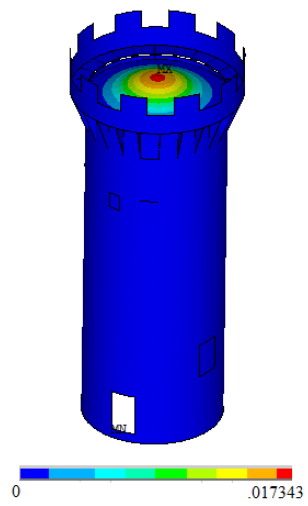

(a)

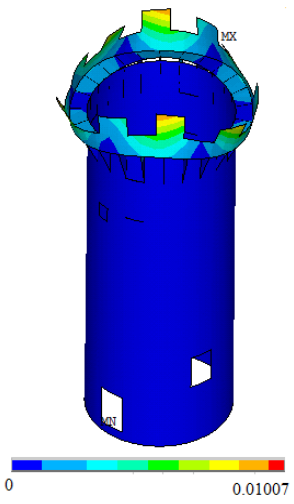

(b)

Figure 6: $\quad$ Mode $7(\mathrm{f}=19.4 \mathrm{~Hz})$ model with slab (a), Mode $14(\mathrm{f}=27.3 \mathrm{~Hz})$ model without slab (b). 


\subsection{Simplified mechanical model}

The tower was subdivided into 5 sectors (fig. 7), according to the presence of the openings and intermediate floors. Obtained the total weight of the building, the horizontal action was evaluated, eqn. (2), prior definition of $\mathrm{T}_{1}$ first period of vibration of the structure deduced from the FEM model and equal to $0.242 \mathrm{~s}$, following the LL.GG. 2011, it is brought back to the cracked condition multiplying it by a factor of 1.4 .

For each sector, the moment resisting $\mathrm{M}_{\mathrm{u}, \mathrm{i}}$ was evaluated and compared to the resulting moment $\mathrm{M}_{\mathrm{e}, \mathrm{i}}$ by horizontal force distributed to the various levels of the tower as a function of the weights of selected sectors, in order to verify the sections to buckling. The results show that the sections in correspondence of the basement are the most vulnerable, with lower resistance moments respect to the acting forces one (table 2). In these sections, the minimum values of spectral acceleration are evaluated determining the crisis by flexural-axial loads.
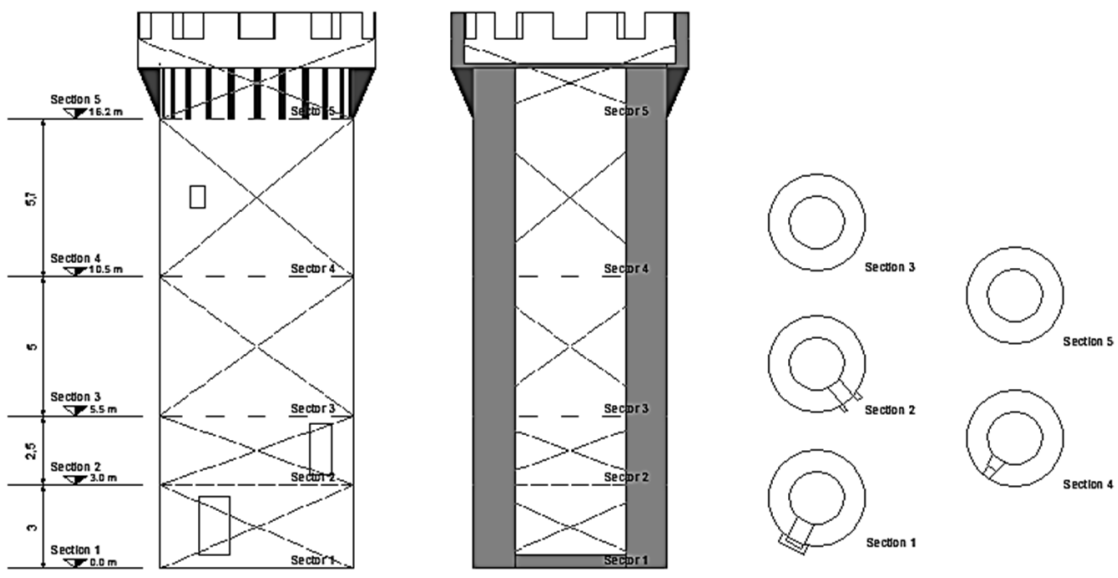

Figure 7: Division of the tower in sectors and check sections.

Table 2: $\quad$ Results of verification respect to flexural-axial loads.

\begin{tabular}{|c|c|c|c|c|c|c|}
\hline Sections & $\mathrm{W}(\mathrm{N})$ & $\mathrm{A}_{\mathrm{i}}\left(\mathrm{m}^{2}\right)$ & $\sigma_{0 \mathrm{i}}\left(\mathrm{N} / \mathrm{m}^{2}\right)$ & $\mathrm{M}_{\mathrm{u}, \mathrm{i}}(\mathrm{Nm})$ & $\mathrm{M}_{\mathrm{e}, \mathrm{i}}(\mathrm{Nm})$ & $\mathrm{M}_{\mathrm{u}, \mathrm{i}} / \mathrm{M}_{\mathrm{e}, \mathrm{i}}$ \\
\hline 1 & 8534880 & 24 & 35552 & 1061908 & 15514217 & 0.68 \\
\hline 2 & 7263144 & 24,3 & 29845 & 1056886 & 11903978 & 0.88 \\
\hline 3 & 6188805 & 26 & 23878 & 1010837 & 9013789 & 1.12 \\
\hline 4 & 3900495 & 23.4 & 16679 & 7851242 & 4069671 & 1.93 \\
\hline 5 & 1546731 & 26 & 59677 & 3717246 & 506123 & 7.35 \\
\hline
\end{tabular}




\subsubsection{FIV-sensitivity analysis}

Through the FIV technique, it is evaluated the influence of the confidence factor Fc on spectral acceleration value that establishes the collapse of the structure. In this way, it is determined how much uncertainty about geometrical and mechanical parameters influences the assessment of vulnerability through the simplified mechanical model.

Table 3: Results of sensitivity analysis, input variation Fc.

\begin{tabular}{|c|c|c|}
\hline Fcj(-) & $\mathrm{S}_{\mathrm{e}, \mathrm{SLV}, \mathrm{i}}(\mathrm{T} 1)(\mathrm{g})$ & $\mathrm{Vj}(-)$ \\
\hline 1 & 0.41 & - \\
\hline 1.03 & 0.40 & 0.97 \\
\hline 1.09 & 0.38 & 0.94 \\
\hline 1.15 & 0.36 & 0.95 \\
\hline 1.2 & 0.34 & 0.96 \\
\hline 1.23 & 0.34 & 0.98 \\
\hline 1.29 & 0.32 & 0.95 \\
\hline 1.35 & 0.31 & 0.96 \\
\hline
\end{tabular}

Eight values of coefficient Fc were considered depending on the variations of the contributions that determine its value in accordance with Italian regulations. Applying eqn. (4), the results in table 3 are obtained.

It is noticed that the calculated variation $V_{j}$ has values close to 1 , then the spectral acceleration would not seem to be affected quite strongly by the variation of the confidence factor Fc. Instead of what occurs in the analysis carried out by varying the values of the resistance of the masonry $f_{d}$, the index $\mathrm{Vj}$ shows a clearly greater sensitivity of the spectral acceleration to vary the material strength.

In table 4 , the results are presented, the analysis has considered the variation of $f_{d}$ in the range values required by LL.GG. 2011, according to literature values for rubble stone masonry in table C8A.2.1 of Appendice C8A [11], starting from a minimum value of $10 \mathrm{daN} / \mathrm{cm}^{2}$ up to a maximum value of $30 \mathrm{daN} / \mathrm{cm}^{2}$.

Table 4: Results of sensitivity analysis, input variation $\mathrm{f}_{\mathrm{d}}$.

\begin{tabular}{|c|c|c|}
\hline $\mathrm{f}_{\mathrm{dj}}\left(\mathrm{daN} / \mathrm{cm}^{2}\right)$ & $\mathrm{S}_{\mathrm{e}, \mathrm{SLV}, \mathrm{i}}(\mathrm{T} 1)(\mathrm{g})$ & $\mathrm{Vj}(-)$ \\
\hline 10 & -0.05 & - \\
\hline 14 & 0.18 & 3.72 \\
\hline 18 & 0.31 & 1.70 \\
\hline 20 & 0.36 & 1.15 \\
\hline 25 & 0.44 & 1.23 \\
\hline 30 & 0.50 & 1.12 \\
\hline
\end{tabular}




\section{Concluding remarks}

Two methods of analysis, modal analysis with FE model and kinematic analysis with a simplified mechanical model, were used to investigate the dynamic behaviour of Torre di S. Stefano di Sessanio to determine the causes of its failure and collapse induced by the earthquake damage.

The modal shapes related to the first ten vibration modes, reveal a global behaviour of the structure strongly linked to its symmetry, as it is noticed by flexural modes coupled. The results of the verification to flexural-axial loads, prove that the failure was on the basement sections. Their resistances are not sufficient to support the heavy loads of the building under the seismic actions. According to observations of the ruins, it must be supposed that the lesion that caused the collapse will be triggered in this area, facilitated by the presence of the openings on the base.

From the results of both analysis, the collapse of the Tower of S. Stefano di Sessanio was determined by a global mechanism of the structure, probably due to a loss of strength of the masonry stem under the effect of a strong seismic excitation. Referring to the most frequently seismic damages for isolated tower, detected by the various post-earthquake inspections, the collapse is considered as an outward rotation of the stem for out-of-plane actions with the formation of cylindrical hinge.

Therefore, the sensitivity analysis was used to identify the uncertainties related to both models, behaviour of the structural elements and knowledge of the material and structural parameters. The presence of structural elements of different construction technology, as the concrete slab, did not influence the overall behaviour of the masonry tower. In the case of the simplified model, the material properties are the most influential in the assessment of the behaviour and of the damage of masonry structure.

Concluding, the simplified mechanical model proposed by Italian Guidelines for evaluation and mitigation of seismic risk, which is normative reference for existing buildings, represents a useful qualitative survey for the evaluation of earthquake damages on historic masonry structures.

\section{References}

[1] Anzani, A., Binda, L., Carpinteri, A., Invernizzi, S., Lacidogna, G., A multilevel approach for the damage assessment of Historic masonry towers. Journal of Cultural Heritage, 11(4), pp. 459-470, 2010.

[2] Boscato, G., Pizzolato, M., Russo, S., Tralli, A., Seismic behavior of a complex historical church in L'Aquila. Int $J$ Architec Heritage, 8(5), pp. 718-57, 2014.

[3] LL.GG. 2011, Linee Guida per la valutazione e riduzione del rischio sismico del patrimonio culturale, Direttiva 09-02-2011.

[4] Di Tommaso, A., Casacci, S., Sopravvivenza di torri e campanili in ambiente sismico, Seminario sul tema "Evoluzione nella sperimentazione per le costruzioni”, CIAS: Creta 93-118, 2013. 
[5] Russo, S., Testing and modelling of dynamic out-of-plane behaviour of the historic masonry façade of Palazzo Ducale in Venice. Engineering Structures, 46, pp. 130-139, 2012.

[6] Ivorra, S., Pallarés, F. J., Adam J. M., Dynamic behaviour of a modern bell tower - A case study. Engineering Structures, 31(5), pp. 1085-1092, 2009.

[7] C. Casalegno, A. Cecchi, E. Reccia, S. Russo. Heterogeneous and continuous models: comparative analysis to investigate masonry wall subjected to differential settlements. Composites: Mechanics, Computations, Applications, 4(3), pp. 187-207, 2013.

[8] Doglioni, F., Moretti, A., Petrini, V., Le Chiese e il terremoto, Edizioni Lint: Trieste; 1994.

[9] Mendes, N., Lourenço, P. B., Sensitivity analysis of the seismic performance of existing masonry buildings. Engineering Structures, ISSN 0141-0296, 2014.

[10] Fassò, A., Perri, P., Sensitivity analysis (Volume 4). Encyclopedia of Envirometrics, edts Abdel H. El-Shaarawi and Walter Piegorsch, John Wiley \& Sons, Ltd, Chichester, pp. 1968-1982, 2002.

[11] Appendice C8A, Circolare 2 febbraio 2009 , n. 617, Gazzetta Ufficiale n. 47 del 26 febbraio 2009 - Suppl. Ordinario n. 27, Ministero delle Infrastrutture e dei Trasporti, 2009. 